\title{
Pneumothorax in patients with idiopathic pulmonary fibrosis: a real-world experience
}

\author{
Ryo Yamazaki, Osamu Nishiyama* (D, Kyuya Gose, Sho Saeki, Hiroyuki Sano, Takashi Iwanaga and Yuji Tohda
}

\begin{abstract}
Background: Some patients with idiopathic pulmonary fibrosis (IPF) develop pneumothorax. However, the characteristics of pneumothorax in patients with IPF have not been elucidated. The purpose of this study was to clarify the clinical course, actual management, and treatment outcomes of pneumothorax in patients with IPF.

Methods: Consecutive patients with IPF who were admitted for pneumothorax between January 2008 and December 2018 were included. The success rates of treatment for pneumothorax, hospital mortality, and recurrence rate after discharge were examined.

Results: During the study period, 36 patients with IPF were admitted with pneumothorax a total of 58 times. During the first admission, 15 patients (41.7\%) did not receive chest tube drainage, but 21 (58.3\%) did. Of the 21 patients, $8(38.1 \%)$ received additional therapy after chest drainage. The respective treatment success rates were $86.6 \%$ and $66.7 \%$ in patients who underwent observation only vs chest tube drainage. The respective hospital mortality rates were 13.3\% and 38.0\%. The total pneumothorax recurrence rate after hospital discharge was $34.6 \%(n=9)$.
\end{abstract}

Conclusions: Pneumothorax in patients with IPF was difficult to treat successfully, had a relatively poor prognosis, and showed a high recurrence rate.

Keywords: Idiopathic pulmonary fibrosis, Hospitalization, Pneumothorax, Recurrence, Treatment

\section{Background}

Idiopathic pulmonary fibrosis (IPF) is a specific form of chronic, progressive and fibrosing lung disease of unknown etiology [1]. The prognosis for patients with IPF is poor, and the median survival is $3-5$ years. However, its natural course is highly variable [2, 3]. Many patients with IPF undergo acute respiratory events such as acute exacerbation (AE), pulmonary infection, pulmonary edema due to heart failure, pulmonary embolism, mediastinal emphysema, and pneumothorax [3-6]. The rates of pneumothorax reportedly range from 2 to $20 \%$ in patients with IPF, which is second highest to the rates occurring in patients with chronic obstructive pulmonary disease (COPD) [7-11]. It has been shown that

*Correspondence: nishiyama_o@yahoo.co.jp

Department of Respiratory Medicine and Allergology, Kindai University

Faculty of Medicine, Osakasayama, Osaka, Japan pneumothorax was significantly associated with poor survival in patients with IPF [11].

In clinical practice, pneumothorax associated with IPF shows a wide range of severity, from mild, involving a small area that does not require any type of treatment, to severe, which is refractory to intervention. The characteristics of pneumothorax in patients with IPF have not been elucidated. This study aimed to clarify the clinical course, actual management, and treatment outcome of pneumothorax in patients with IPF.

\section{Methods \\ Patients}

We retrospectively reviewed the clinical records of all patients with IPF who were first admitted for pneumothorax to the Kindai University Hospital from January 2008 to December 2019. The diagnosis of IPF was made according to the classification used in the INPULSIS 
trial [12]. Briefly, patients who had histological evidence of a usual interstitial pneumonia pattern on a surgical lung biopsy specimen were included. In the absence of a biopsy specimen, patients with the following findings on high-resolution computed tomography (HRCT) were diagnosed with IPF: honeycombing and/or the presence of reticular abnormality and traction bronchiectasis without features suggestive of alternative causes. Patients with concomitant pleuroparenchymal fibroelastosis (PPFE) were excluded.

\section{Data collection}

We recorded the clinical characteristics of all the study patients, which included the following: findings on physical examination, standard laboratory tests performed on admission, use of long-term oxygen therapy (LTOT), and treatments for IPF. Pulmonary function tests performed within 1 year prior to admission were used for assessment of baseline pulmonary function. We also assessed the specific treatments for pneumothorax.

\section{Successful treatment for pneumothorax}

Treatments for pneumothorax were evaluated with regard to whether or not they were successful. Successful management of pneumothorax was defined as hospital discharge without a chest tube. A successful chest tube treatment was defined as removal of the chest tube.

\section{Survival assessment}

In-hospital deaths and deaths after discharges were retrospectively obtained from the study patients' hospital charts.

\section{Recurrence of pneumothorax after first discharge from the hospital for successful treatment of first pneumothorax}

Data on recurrence of pneumothorax was assessed. The time to recurrence was defined as the number of days from the date of discharge from the first pneumothorax until the date of admission for recurrence of pneumothorax. Contralateral pneumothorax was not included in the recurrence.

\section{Statistical analysis}

Continuous variables were expressed as means \pm standard deviation (SD). Categorical variables were expressed as frequencies. We performed logistic regression analysis to determine predictors of hospital death. $P$ values less than 0.05 were considered statistically significant. The median duration of survival after discharge was estimated on a Kaplan-Meier survival curve. Statflex ver.6 software (Artech, CO., Ltd., Osaka, Japan) was used for analysis.

\section{Results}

During the survey period, 36 patients with IPF were admitted to our university hospital for pneumothorax a total of 58 times. The characteristics of the patients before their first admission are shown in Table 1. This study included 29 men and 7 women. The mean age of the study patients was $75.5 \pm 5.4$ years, and the mean body mass index was $18.5 \pm 4.1 \mathrm{~kg} / \mathrm{m}^{2}$. The mean forced vital capacity (FVC) was $55.8 \% \pm 16.5 \%$ predicted and the mean diffusing capacity for carbon monoxide (DLco) was $62.4 \% \pm 14.9 \%$ predicted. Twenty-six patients $(72.2 \%)$ had a smoking history. Seven patients (19.4\%) were receiving corticosteroids for IPF.

The clinical data of study patients at the first admission are shown in Table 2. The mean values for Krebs von der Lungen-6 (KL-6), partial pressure of arterial oxygen/fraction of inspiratory oxygen $\left(\mathrm{PaO}_{2} / \mathrm{FiO}_{2}\right)$, and partial pressure of arterial carbon dioxide $\left(\mathrm{PaCO}_{2}\right)$ were $957 \pm 744 \mathrm{U} / \mathrm{mL}, 295 \pm 100$, and $46.8 \pm 9.8 \mathrm{~mm} \mathrm{Hg}$, respectively.

Table 1 Baseline characteristics of the study patients and treatments for IPF before the first admission for pneumothorax

\begin{tabular}{|c|c|}
\hline Characteristics & $N=36$ \\
\hline Age, year & $75.5 \pm 5.4$ \\
\hline \multicolumn{2}{|l|}{ Gender } \\
\hline Male/female & $29 / 7$ \\
\hline Body mass index ${ }^{a}, \mathrm{~kg} / \mathrm{m}^{2}$ & $18.5 \pm 4.1$ \\
\hline \multicolumn{2}{|l|}{ Preadmission of PFT } \\
\hline$F V C^{b}, L$ & $1.6 \pm 0.6$ \\
\hline $\mathrm{FVC}^{\mathrm{b}}, \%$ predicted & $55.8 \pm 16.5$ \\
\hline $\mathrm{FEV}_{1}^{\mathrm{b}}, \mathrm{L}$ & $1.5 \pm 0.5$ \\
\hline $\mathrm{FEV}_{1}{ }^{\mathrm{b}}, \%$ predicted & $66.2 \pm 18.4$ \\
\hline $\mathrm{FEV}_{1} / \mathrm{FVC}^{\mathrm{b}}, \%$ & $91.7 \pm 10.6$ \\
\hline $\mathrm{DLCO}^{\mathrm{c}}, \mathrm{mL} / \mathrm{min} / \mathrm{mmHg}$ & $8.3 \pm 2.2$ \\
\hline DLCo ${ }^{c}, \%$ predicted & $62.4 \pm 14.9$ \\
\hline \multicolumn{2}{|l|}{ Smoking status } \\
\hline Current/former/never & $1 / 25 / 10$ \\
\hline \multicolumn{2}{|c|}{ Treatment for IPF at baseline } \\
\hline Pirfenidone & 4 \\
\hline Nintedanib & 3 \\
\hline Corticosteroid & 7 \\
\hline Cyclosporine & 4 \\
\hline None & 22 \\
\hline \multicolumn{2}{|l|}{ Long-term oxygen therapy } \\
\hline Yes/no & $9 / 27$ \\
\hline
\end{tabular}

Values are shown as actual numbers or means \pm standard deviation $\mathrm{N}=36\left({ }^{\mathrm{a}} \mathrm{N}=35,{ }^{\mathrm{b}} \mathrm{N}=27,{ }^{\mathrm{c}} \mathrm{N}=12\right)$

DLco, diffusing capacity for carbon monoxide; $\mathrm{FEV}_{1}$, forced expiratory volume in $1 \mathrm{~s}$; FVC, forced vital capacity; IPF, idiopathic pulmonary fibrosis; PFT, pulmonary function tests 


\begin{tabular}{lc}
$\begin{array}{l}\text { Table } 2 \text { Clinical data } \\
\text { for pneumothorax }\end{array}$ & at the \\
\hline Variable & $\mathbf{N}=\mathbf{3 6}$ \\
\hline $\mathrm{KL}-6^{\mathrm{a}}, \mathrm{U} / \mathrm{mL}$ & $972 \pm 744$ \\
Arterial blood gas & \\
$\mathrm{pH}^{\mathrm{b}}$ & $7.39 \pm 0.06$ \\
$\mathrm{PaO}_{2} / \mathrm{FiO}_{2}$ ratio $^{\mathrm{b}}$ & $295 \pm 100$ \\
$\mathrm{PaCO}_{2}{ }^{\mathrm{b}}, \mathrm{mmHg}$ & $46.8 \pm 9.8$ \\
\hline
\end{tabular}

Values are shown as actual numbers or means \pm standard deviation $\mathrm{N}=36\left({ }^{\mathrm{a}} \mathrm{N}=28,{ }^{\mathrm{b}} \mathrm{N}=33\right)$

$\mathrm{KL}-6, \mathrm{Krebs}$ von der Lungen-6; $\mathrm{PaCO}_{2}$, partial pressure of arterial carbon dioxide; $\mathrm{PaO}_{2} / \mathrm{FiO}_{2}$, partial pressure of arterial oxygen/fraction of inspiratory oxygen

The success rates of each treatment for pneumothorax administered during the first admission and the success rates of each treatment administered during the first combined with all of the subsequent admissions of the study patients for recurrent pneumothorax are shown in Table 3. During the first admission, 15 patients (41.7\%) did not undergo and 21 (58.3\%) underwent chest tube drainage. Of the 21 patients undergoing drainage, $8(38.1 \%)$ received additional therapy after drainage. The additional therapies included placement of an endobronchial Watanabe spigot (EWS) and pleurodesis with fibrin glue and/or a blood patch. The respective rates of successful treatment after the first admission were $86.6 \%$ and $66.7 \%$ in patients who underwent observation only or underwent chest tube drainage. The respective rates of success after the first admission of chest tube drainage plus the additional therapy of EWS placement or plus pleurodesis $(\mathrm{n}=2)$ after the first admission were $57.1 \%(\mathrm{n}=7)$ and $50.0 \%(n=2)$. The total success rate of each treatment administered during all of the admissions was similar to the success rate of each treatment during the first admission only. In patients whose chest tube could be removed, the mean lengths of time until removal for the first admission and total number of admissions were $20.7 \pm 14.0$ and $23.6 \pm 18.5$ days, respectively. Some patients remained hospitalized even after the chest tube was removed, mainly because of subsequent type 2 respiratory failure and/or pulmonary infection.

The hospital mortality rates for the first admission and for all the admissions combined were $27.7 \%$ and $24.1 \%$, respectively (Table 4 ). The mean durations of hospitalization for the first and total number of admissions were $34.2 \pm 27.5$ days and $31.0 \pm 28.5$ days, respectively. Hospital mortality rates were higher in patients who underwent chest tube drainage than in patients who did not undergo drainage during both the first admission and during the total number of admissions, although the differences were not significant.

The recurrence rates of pneumothorax in patients who were discharged alive are shown in Table 5. Pneumothorax recurred in 9 of $26(34.6 \%)$ patients discharged alive after the first admission. Among the 9 patients, 8 patients $(8.8 \%)$ recurred within 1 year. Differences between recurrence rates after each treatment were not significant. However, the recurrence rates tended to be higher in patients who had undergone chest drainage plus additional therapy.

None of the variables assessed at admission and none of the types of treatments were identified as significant predictors of hospital mortality. The estimated median duration of survival was 154 days after discharge of the first admission among patients who could discharge alive.

Table 3 Rates of successful treatment for pneumothorax without surgical intervention

\begin{tabular}{|c|c|c|c|c|}
\hline \multirow[t]{2}{*}{ Treatment } & \multicolumn{2}{|c|}{ First admission } & \multicolumn{2}{|c|}{ Total admission } \\
\hline & $\begin{array}{l}\text { Number } \\
\text { of patients }\end{array}$ & $\begin{array}{l}\text { Number of patients } \\
\text { successfully treated (\%) }\end{array}$ & $\begin{array}{l}\text { Number } \\
\text { of patients }\end{array}$ & $\begin{array}{l}\text { Number of patients } \\
\text { successfully treated } \\
(\%)\end{array}$ \\
\hline All patients & 36 & $27(75.0)$ & 58 & $49(84.4)$ \\
\hline Observation only & 15 & $13(86.6)$ & 29 & $26(89.6)$ \\
\hline Chest tube & 21 & $14(66.7)$ & 29 & $17(58.6)$ \\
\hline Chest tube only & 13 & $9(69.2)$ & 15 & $10(66.6)$ \\
\hline Chest tube plus additional therapy & $8^{*}$ & $5(62.5)$ & $12^{*}$ & $7(58.3)$ \\
\hline EWS placement & 7 & $4(57.1)$ & 10 & $5(50.0)$ \\
\hline $\begin{array}{l}\text { Pleurodesis with fibrin glue and/or blood } \\
\text { patch }\end{array}$ & 2 & $1(50.0)$ & 3 & $2(66.6)$ \\
\hline
\end{tabular}

Two patients during the first admission and 4 during all admissions combined underwent surgery after chest tube placement and some additional therapies resulting in chest tube removal

* One patient underwent EWS followed by pleurodesis

EWS, endoscopic Watanabe spigot 
Table 4 Hospital mortality according to treatments for pneumothorax and success of chest tube removal

\begin{tabular}{lllllc}
\hline & \multicolumn{2}{l}{ First admission } & & \multicolumn{2}{l}{ Total admission } \\
\cline { 2 - 3 } & Number of patients & Hospital death (\%) & & Number of patients & Hospital death (\%) \\
\hline All patients & 36 & $10(27.7)$ & $2(13.3)$ & 58 & $14(24.1)$ \\
Observation only & 15 & $8(38.0)$ & $3(21.4)$ & 29 & $3(10.3)$ \\
Chest tube & 21 & $5(100)$ & 29 & $11(37.9)$ \\
$\quad$ Successful chest tube removal & 14 & $0(0)$ & 8 & $3(17.6)$ \\
Failure of chest tube removal & 5 & & 4 & $8(100)$ \\
Removed with surgery & 2 & & & & 0 \\
\hline
\end{tabular}

Table 5 Relationships between treatment for pneumothorax and recurrence in patients who were discharged alive

\begin{tabular}{|c|c|c|c|c|}
\hline \multirow[t]{2}{*}{ Treatment for the pneumothorax } & \multicolumn{2}{|l|}{ First admission } & \multicolumn{2}{|l|}{ Total admissions } \\
\hline & Number of patients & $\begin{array}{l}\text { Number of patients } \\
\text { recurring (\%) }\end{array}$ & Number of patients & $\begin{array}{l}\text { Number } \\
\text { of patients } \\
\text { recurring (\%) }\end{array}$ \\
\hline All patients & $26^{*}$ & $9(34.6)^{\dagger}$ & $44^{*}$ & $14(31.8)^{\dagger}$ \\
\hline Observation only & 13 & $5(38.4)$ & 26 & $10(38.4)$ \\
\hline Chest tube & 13 & $4(30.7)$ & 18 & $4(22.2)$ \\
\hline Chest tube only & 7 & $2(28.5)$ & 9 & $2(22.2)$ \\
\hline Chest tube plus additional therapy & $4^{\ddagger}$ & $2(50.0)$ & $5^{\S}$ & $2(40.0)$ \\
\hline Surgery** & 2 & $0(0)$ & 4 & $0(0)$ \\
\hline
\end{tabular}

The last treatments in the admission were listed

EWS, endoscopic Watanabe spigot

* Including 2 patients with bilateral pneumothorax

** One patient (50\%) recurred among the patients who underwent surgery during the first admission. One patient recurred (25.0\%) among the patients who underwent surgery during all the admissions combined

${ }^{+}$Including 1 patient with bilateral pneumothorax

₹ Three patients underwent EWS after chest tube drainage. One patient underwent blood patch pleurodesis and fibrin glue pleurodesis after chest tube drainage

$\S$ Four patients underwent EWS after chest tube drainage. One patient underwent blood patch pleurodesis and fibrin glue pleurodesis after chest tube drainage

\section{Discussion}

Pneumothorax can occur in patients with underlying lung diseases; its rate of frequency is highest in patients with COPD and second-highest in those with interstitial pneumonia [10]. Pneumothorax that occurs in patients with chronic lung disease is reportedly associated with higher mortality and recurrence rates than primary spontaneous pneumothorax that occurs in patients without chronic lung disease $[9,10,13]$. Our study shows that pneumothorax in patients with IPF was difficult to treat successfully, shows a high recurrence rate, and has a relatively poor prognosis.

The insertion of a chest tube for the initial management of secondary pneumothorax warrants discussion. In our study, some patients did not undergo chest tube drainage. The British Thoracic Society (BTS) recommends insertion of a chest tube when the depth of the pneumothorax from the chest wall is $>2 \mathrm{~cm}$ and/or when the patient shows signs and symptoms of pneumothorax [14]. When the depth is $\leq 2 \mathrm{~cm}$, temporal aspiration or observation with oxygen inhalation are recommended. In our hospital, we generally followed the recommendations of the BTS, although insertion of a chest tube was ultimately performed based on the treating physician's judgement.

The BTS recommends surgery for patients with a persistent air leak from the chest tube placed for drainage [14]. However, some patients with secondary spontaneous pneumothorax are not candidates for surgical intervention because of age, poor pulmonary function, or other comorbidities. In addition, acute exacerbation of IPF can occur after surgery [15]. Actually, only 2 patients during the first admission and 4 during all the admissions combined underwent surgery after chest tube drainage, plus additional treatments. Successful thoracoscopic surgery for intractable pneumothorax under local and epidural anesthesia was reported [16]. V-V ECMO utilization for such a difficult case was also reported [17]. However, no patients underwent surgery with such strategies in the present study. 
Chemical pleurodesis can be a nonsurgical option for patients with persistent air leakage from the chest tube [14]. Complete re-expansion of the lung is needed to achieve successful chemical pleurodesis. However, some IPF patients with pneumothorax do not obtain reexpansion of the lung because of the distinctive rigidity of the lung parenchyma in IPF [18]. Another concern with chemical pleurodesis is the risk of restrictive pulmonary dysfunction [19] and acute exacerbation of IPF after the procedure [20]. Probably for these reasons, chemical pleurodesis was not performed for any of the study patients. As another nonsurgical option, pleurodesis performed with an autologous-blood patch or fibrin glue has been reported to be effective [21,22]. Although adequate pulmonary re-expansion is needed to achieve pleurodesis, the risks of restrictive pulmonary dysfunction and acute exacerbation of IPF after these procedures might be lower than they are after chemical pleurodesis. In our patient series, a respective 2 patients during the first admission and 3 patients during all the admissions combined underwent pleurodesis by fibrin glue or autologous blood patch for success rates of $50 \%$ and $66 \%$.

An EWS is a silicone spigot used to occlude a bronchus [23]. The EWS has been reported to be effective for reducing air leakage in about $50 \%$ of patients [24]. In our study, the EWS showed relatively high success rates of $57.1 \%$ and $50.0 \%$ for the first and all the admissions combined, respectively. Given that the EWS has been found to be useful even in patients who have incomplete re-expansion of the lung, placement of an EWS might be suitable for patients with IPF and pneumothorax with persistent air leakage from the chest tube. However, placement of the EWS requires sedation and intubation of the patient. Poor lung function and/or low oxygenation might indicate that a patient would not tolerate the procedure. Criteria for safely performing placement of an EWS need to be established.

Hospital mortality rates of patients with secondary spontaneous pneumothorax have been reported to range from $4.5 \%$ to $17.9 \%$ [10, 25]. In these reports, the most frequent underlying disease was pulmonary emphysema. By contrast, a higher hospital mortality rate has been reported for pneumothorax in patients with IPF [6]. The hospital mortality rates in our study ranged from 24 to $28 \%$, which were relatively high, although similar to the previous report [6]. The mortality of patients who required chest tube drainage was even higher in our study.

The recurrence rate of secondary spontaneous pneumothorax varies according to the published literature, ranging from 30 to $80 \%[14,25,26]$. The recurrence rate of pneumothorax in patients with IPF is reportedly high (70.6\%) [11]. In our study, $34.6 \%$ of patients with IPF developed recurrence after their first admission and subsequent discharge for pneumothorax. Furthermore, the majority of recurrences were observed within the first year after discharge. Given that recurrence of pneumothorax in a patient with IPF confers additional risk of death, preventative methods for recurrence should be developed.

This study has limitations. First, it was a single-center retrospective study of a relatively small number of patients. Second, the treatment for pneumothorax was not uniform because it was performed by individual physicians and based on their individual judgements. Third, the study might have included patients with PPFE $[27,28]$. Although major efforts were made to exclude patients with PPFE based on the chest HRCT, some patients with subclinical PPFE could have been included. Histological PPFE seen in the upper pulmonary lobes was reported to trigger pneumothorax in patients with IPF [29]. Further studies of pneumothorax in IPF patients should preferably base study enrollment on a histological evaluation of a lung specimen.

To the best of our knowledge, the study is the first to evaluate additional treatments in IPF patients with pneumothorax and persistent air leakage after placement of a chest drain. The efficacy of combined therapy, consisting of treatments in addition to chest tube drainage should be improved.

\section{Conclusions}

Pneumothorax in patients with IPF is difficult to treat successfully, and has a relatively poor prognosis and high recurrence rate.

\section{Abbreviations}

AE: Acute exacerbation; COPD: Chronic obstructive pulmonary disease; DLco: Diffusing capacity for carbon monoxide; EWS: Endobronchial Watanabe spigot; HRCT: High-resolution computed tomography; IPF: Idiopathic pulmonary fibrosis; KL-6: Krebs von der Lungen-6; LTOT: Long-term oxygen therapy; $\mathrm{PaCO}_{2}:$ Partial pressure of arterial carbon dioxide; $\mathrm{PaO}_{2} / \mathrm{FiO}_{2}:$ Partial pressure of arterial oxygen/fraction of inspiratory oxygen; PPFE: Pleuroparenchymal fibroelastosis.

\section{Acknowledgements \\ Not applicable.}

\section{Authors' contributions}

Manuscript conception and design: R.Y., O.N.; data collection and data analysis: R.Y., K.G., S.S.; data interpretation: R.Y., O.N.; project administration: Y.T.; writing the manuscript draft: R.Y.; critical revision and editing the final manuscript: O.N., H.S., T.I. Guarantor of this manuscript; Y.T. All authors read and approved the final manuscript.

\section{Funding}

This research did not receive any specific grant from funding agencies in the public, commercial, or not-for-profit sectors.

Availability of data and materials

The datasets used and/or analyzed during the current study are available from the corresponding author upon reasonable request. 


\section{Ethics approval and consent to participate}

Informed consent was waived, because this study was based on a retrospective analysis of case records from our university hospital. Approval for the use of these data and the analysis was provided by the ethics committee of the Kindai University Faculty of Medicine (No. 31-271).

\section{Consent for publication}

Not applicable.

\section{Competing interests}

There are no conflicts of interest to declare in relation to this article.

Received: 3 June 2020 Accepted: 11 December 2020

Published online: 06 January 2021

\section{References}

1. Raghu G, Remy-Jardin M, Myers JL, Richeldi L, Ryerson CJ, Lederer DJ, et al Diagnosis of idiopathic pulmonary fibrosis. An official ATS/ERS/JRS/ALAT clinical practice guideline. Am J Respir Crit Care Med. 2018;198:e44-68.

2. Raghu G, Collard HR, Egan JJ, Martinez FJ, Behr J, Brown KK, et al. An official ATS/ERS/JRS/ALAT statement: idiopathic pulmonary fibrosis: evidence-based guidelines for diagnosis and management. Am J Respir Crit Care Med. 2011;183:788-824.

3. Martinez FJ, Safrin S, Weycker D, Starko KM, Bradford WZ, King TE Jr, et al. The clinical course of patients with idiopathic pulmonary fibrosis. Ann Intern Med. 2005;142:963-7.

4. Song JW, Hong SB, Lim CM, Koh Y, Kim DS. Acute exacerbation of idiopathic pulmonary fibrosis: incidence, risk factors and outcome. Eur Respir J. 2011;37:356-63.

5. Brown AW, Fischer CP, Shlobin OA, Buhr RG, Ahmad S, Weir NA, et al. Outcomes after hospitalization in idiopathic pulmonary fibrosis: a cohort study. Chest. 2015;147:173-9.

6. Cottin V, Schmidt A, Catella L, Porte F, Fernandez-Montoya C, Le Lay K, et al. Burden of idiopathic pulmonary fibrosis progression: a 5-year longitudinal follow-up study. PLoS ONE. 2017;12:e0166462.

7. Noppen M. Spontaneous pneumothorax: epidemiology, pathophysiology and cause. Eur Respir Rev. 2010;19:217-9.

8. Chen CH, Liao WC, Liu YH, Chen WC, Hsia TC, Hsu WH, Shih CM, Tu CY. Secondary spontaneous pneumothorax: which associated conditions benefit from pigtail catheter treatment? Am J Emerg Med. 2012;30(1):45-50.

9. Guo Y, Xie C, Rodriguez RM, Light RW. Factors related to recurrence of spontaneous pneumothorax. Respirology. 2005;10:378-84.

10. Takuya O, Sho U, Masatoshi Y, Yoshiaki S, Hitoshi Y, Naoki K, et al. Primary and secondary spontaneous pneumothorax: prevalence, clinical features, and in-hospital mortality. Can Respir J. 2017;2017:6014967.

11. Nishimoto K, Fujisawa T, Yoshimura K, Enomoto Y, Enomoto N, Nakamura $Y$, et al. The prognostic significance of pneumothorax in patients with idiopathic pulmonary fibrosis. Respirology. 2018;23:519-25.

12. Richeldi L, du Bois RM, Raghu G, Azuma A, Brown KK, Costabel U, et al. Efficacy and safety of nintedanib in idiopathic pulmonary fibrosis. N Engl J Med. 2014;370:2071-82.
13. Gupta D, Hansell A, Nichols T, Duong T, Ayres J, Strachan D. Epidemiology of pneumothorax in England. Thorax. 2000;55:666-71.

14. MacDuff A, Arnold A, Harvey J, BTS Pleural Disease Guideline Group. Management of spontaneous pneumothorax: British Thoracic Society pleural disease guideline 2010. Thorax. 2010;65:ii18-31.

15. Choi SM, Lee J, Park YS, Cho YJ, Lee CH, Lee SM, et al. Postoperative pulmonary complications after surgery in patients with interstitial lung disease. Respiration. 2014;87:287-93

16. Noda M, Okada Y, Maeda S, Kondo T. Successful thoracoscopic surgery for intractable pneumothorax after pneumonectomy under local and epidural anesthesia. J Thorac Cardiovasc Surg. 2011;141:1545-7.

17. Oey IF, Peek GJ, Firmin RK, Waller DA. Post-pneumonectomy videoassistedthoracoscopic bullectomy using extra-corporeal membrane oxygenation. Eur J Cardiothorac Surg. 2001;20:874-6.

18. Picado C, Gómez de Almeida R, Xaubet A, Montserrat J, Letang E, Sánchez-Lloret J. Spontaneous pneumothorax in cryptogenic fibrosing alveolitis. Respiration. 1985;48:77-80.

19. Lange P, Mortensen J, Groth S. Lung function 22-35 years after treatment of idiopathic spontaneous pneumothorax with talc poudrage or simple drainage. Thorax. 1988:43:559-61.

20. Rodriguez-Panadero F, Montes-Worboys A. Mechanisms of pleurodesis. Respiration. 2012;83:91-8.

21. Manley K, Coonar A, Wells F, Scarci M. Blood patch for persistent air leak: a review of the current literature. Curr Opin Pulm Med. 2012;18:333-8.

22. Kinoshita T, Miyoshi S, Katoh M, Yoshimasu T, Juri M, Maebeya S, et al. Intrapleural administration of a large amount of diluted fibrin glue for intractable pneumothorax. Chest. 2000;117:790-5.

23. Watanebe Y, Matso K, Tamaoki A, Kamoto R, Hiraki S. Bronchial occlusion with endobronchial Watanabe spigot. J Bronchol. 2003;10:264-7.

24. Sasada S, Tamura K, Chang YS, Okamoto N, Matsuura Y, Tamiya M, et al. Clinical evaluation of endoscopic bronchial occlusion with silicone spigots for the management of persistent pulmonary air leaks. Intern Med. 2011;50(11):1169-73.

25. Tanaka F, Itoh M, Esaki H, Isobe J, Ueno Y, Inoue R. Secondary spontaneous pneumothorax. Ann Thorac Surg. 1993;55:372-6.

26. Iga $\mathrm{N}$, Nishi H, Fujimoto N, Kishimoto T. Clinical features of secondary spontaneous pneumothorax complicated with silicosis. Respir Investig. 2018;56:144-9.

27. Frankel SK, Cool CD, Lynch DA, Brown KK. Idiopathic pleuroparenchymal fibroelastosis: description of a novel clinicopathologic entity. Chest. 2004; 126:2007.

28. Travis WD, Costabel U, Hansell DM, King TE Jr, Lynch DA, Nicholson AG, et al. An official American Thoracic Society/European Respiratory Society statement: update of the international multidisciplinary classification of the idiopathic interstitial pneumonias. Am J Respir Crit Care Med. 2013:188:733-48

29. Bonifazi M, Montero MA, Renzoni EA. Idiopathic pleuroparenchymal fibroelastosis. Curr Pulmonol Rep. 2017;6:9-15.

\section{Publisher's Note}

Springer Nature remains neutral with regard to jurisdictional claims in published maps and institutional affiliations.

Ready to submit your research? Choose BMC and benefit from

- fast, convenient online submission

- thorough peer review by experienced researchers in your field

- rapid publication on acceptance

- support for research data, including large and complex data types

- gold Open Access which fosters wider collaboration and increased citations

- maximum visibility for your research: over 100M website views per year

At $\mathrm{BMC}$, research is always in progress.

Learn more biomedcentral.com/submissions 